\title{
Crescimento e atividade de raízes de soja em função do sistema de produção
}

\author{
Laércio Augusto Pivetta(1), Gustavo Castoldi(1), Gabriel Peixoto dos Santos ${ }^{(1)}$ e Ciro Antonio Rosolem ${ }^{(1)}$ \\ (1)Universidade Estadual Paulista, Faculdade de Ciências Agronômicas, Campus de Botucatu, Caixa Postal 237, CEP $18603-970$ Botucatu, SP. \\ E-mail: laerciopivetta@fca.unesp.br, castoldi@fca.unesp.br, gpdsantos@fca.unesp.br, rosolem@fca.unesp.br
}

Resumo - O objetivo deste trabalho foi determinar o efeito de culturas de inverno e de primavera no crecimento do sistema radicular e na produtividade da soja, e comparar um método direto (trado) com um indireto (com rubídio), na análise do sistema radicular. Utilizou-se o delineamento experimental de blocos ao acaso, em parcelas subdivididas, com quatro repetições. As parcelas foram constituídas pelas culturas de inverno, triticale (X Triticosecale) e girassol (Helianthus annuus), e as subparcelas pelos culturas de primavera, milheto (Pennisetum glaucum), sorgo forrageiro (Sorghum bicolor) e crotalária júncea (Crotalaria juncea), além da escarificação, realizada em 2003 e 2009. A soja (Glycine max) foi cultivada no verão e seu sistema radicular foi avaliado por amostragem física das raízes, com trado, e por avaliação da atividade radicular com rubídio. Modificações na arquitetura ou na atividade do sistema radicular da soja não afetaram a produtividade. A distribuição física e a atividade radicular não foram afetados significativamente pelas espécies de inverno, mas o crescimento foi favorecido após o cultivo do milheto e do sorgo forrageiro, na primavera. A medida direta do sistema radicular com trado apresenta baixa correlação com a atividade radicular.

Termos para indexação: Glycine max, compactação do solo, escarificação, marcação com rubídio, plantas de cobertura, sistema radicular.

\section{Soybean root growth and activity as affected by the production system}

\begin{abstract}
The objective of this work was to assess winter and spring crop effects on soybean root system growth, and on yield, and to compare a direct method (soil core sampling) with an indirect method (with rubidium) in evaluating the root system. The experimental design was a randomized complete block design, in a split-plot arrangement, with four replicates. Plots consisted of the winter crops, triticale (X Triticosecale) and sunflower (Helianthus annuus), and subplots of the spring crops, pearl millet (Pennisetum glaucum), forage sorghum (Sorghum bicolor) and sunn hemp (Crotalaria juncea), besides chisel tillage in 2003 and 2009. Soybean (Glycine max) was grown in the summer, and its root system was evaluated by physical sampling of the roots and by root activity assessment using rubidium. Changes in the architecture or in the activity of soybean roots did not affect yield. The distribution and activity of soybean roots were not significantly affected by the winter cover crops, but root growth was favored after millet and sorghum were grown in the spring. The direct measurement of the soybean root system with an auger has low correlation with root activity.
\end{abstract}

Index terms: Glycine max, soil compaction, chiseling, rubidium tracer, cover crops, root system.

\section{Introdução}

O sistema radicular das plantas deve apresentar bom desenvolvimento em volume e boa arquitetura para otimizar a utilização dos recursos disponíveis (Lynch, 1995; Taiz \& Zeiger, 2004).

O sistema de semeadura direta é uma técnica eficiente no controle da erosão quando comparado com o sistema convencional (Bertol et al., 1997); no entanto, tem-se observado maior compactação superficial do solo (Genro Junior et al., 2004), geralmente na camada de 0,07-0,15 m (Stone \& Silveira, 2001).
Quando o sistema radicular atinge essa camada, ocorre proliferação de raízes secundárias na camada acima da compactada, mas o crescimento é reduzido no subsolo, o que pode limitar a absorção de água e nutrientes e reduzir a produtividade das culturas (Hamza \& Anderson, 2005).

A descompactação em sistema de semeadura direta pode ser realizada por métodos mecânicos ou biológicos. Entre os processos mecânicos, os implementos com hastes são os mais adequados, pois produzem superfícies mais rugosas, apresentam menor superfície de contato e menor poder desagregador

Pesq. agropec. bras., Brasília, v.46, n.11, p.1547-1554, nov. 2011 
do solo, além de manterem maior quantidade de restos culturais em superfície (Carvalho Filho et al., 2007). Contudo, após a escarificação, o solo volta a se reconsolidar com facilidade (Hamza \& Anderson, 2005). Entre os métodos biológicos, destaca-se a rotação de culturas, que pode ser utilizada tanto na prevenção quanto no controle da compactação, desde que utilizadas espécies com sistema radicular vigoroso, com capacidade de crescer em camadas com alta resistência à penetração, criando poros por onde as raízes da cultura subsequente possam crescer (Silva \& Rosolem, 2002; Muzilli, 2006).

Como o crescimento das raízes é influenciado pelo manejo do solo, a avaliação do sistema radicular de uma cultura é importante para o desenvolvimento de práticas agrícolas que visam à otimização da produtividade (Fante Júnior et al., 1994). Os métodos diretos de análise radicular são mais comumente usados; porém, são mais trabalhosos e, muitas vezes, podem levar a interpretações errôneas a respeito da utilização dos recursos do solo, pois normalmente não distinguem raízes mortas de vivas e dificilmente evitam perdas das raízes mais finas, responsáveis por fração considerável da absorção de nutrientes (Russell \& Ellis, 1968). Portanto, métodos indiretos, que representam a distribuição da atividade radicular por meio de marcadores, podem ser mais adequados. Ao comparar o sistema convencional à semeadura direta, Barrios et al. (2006) observaram que maior produtividade é obtida no sistema que proporciona a maior atividade radicular, ou seja, o sistema convencional, para a soja, e a semeadura direta para o milho. Contudo, a avaliação do sistema radicular da soja por apenas um método torna difícil concluir qual sistema seria realmente o mais adequado. Não foram encontrados, na literatura, trabalhos com a avaliação do crescimento e da atividade radicular por meio da utilização simultânea de métodos indiretos e diretos.

O objetivo deste trabalho foi avaliar o efeito de culturas de inverno e de primavera no sistema radicular e na produtividade da soja, e comparar um método direto (trado) com um indireto (com rubídio), na análise do sistema radicular.

\section{Material e Métodos}

As avaliações foram realizadas de março de 2009 a março de 2010, em experimento que vinha sendo conduzido desde 2003, na Fazenda Experimental
Lageado, em Botucatu, SP $\left(22^{\circ} 49^{\prime}\right.$ S e $48^{\circ} 25^{\prime} \mathrm{W}$, altitude média de $770 \mathrm{~m}$ ). O clima do local, de acordo com a classificação de Köppen, é do tipo Cwa, mesotérmico úmido, com precipitação média anual em torno de $1.400 \mathrm{~mm}$ e temperatura média do mês mais quente superior a $22^{\circ} \mathrm{C}$, e do mês mais frio entre 3 e $18^{\circ} \mathrm{C}$. $\mathrm{O}$ solo da área experimental é classificado como Nitossolo Vermelho distroférrico, estruturado, de textura argilosa (Santos et al., 2006).

Utilizou-se o delineamento de blocos ao acaso, com parcelas subdivididas, com quatro repetições. As parcelas foram constituídas pelas culturas de inverno, triticale (X Triticosecale Wittmack) e girassol (Helianthus annuus L.), e as subparcelas pelas culturas do milheto (Pennisetum glaucum L.), do sorgo forrageiro (Sorghum bicolor (L.) Moench) e da crotalária júncea (Crotalaria juncea L.), semeadas na primavera, além da escarificação, realizada em 2003 e repetida em 2009. A soja (Glycine max L.) foi cultivada no verão. As parcelas apresentavam as dimensões de $32 \times 12 \mathrm{~m}$, e a área útil das subparcelas era de $40 \mathrm{~m}^{2}$ (8x5 m). Em abril de 2009, foram semeadas as culturas de inverno, ambas sem adubação, com espaçamento entre linhas de $0,51 \mathrm{~m}$, para o girassol, e de $0,17 \mathrm{~m}$ para o triticale. A escarificação foi realizada em setembro de 2009, com escarificador de sete hastes, equipado com disco de corte e cilindro destorroador. As hastes foram espaçadas em $0,35 \mathrm{~m}$, com profundidade de trabalho de $0,30 \mathrm{~m}$.

Após a escarificação e antes da semeadura das plantas de cobertura, realizou-se amostragem de solo, para análise química, em toda a área experimental, na camada de $0,0-0,2 \mathrm{~m}$, que apresentou os seguintes resultados (Raij et al., 2001): $\mathrm{pH}\left(\mathrm{CaCl}_{2}\right) 4,2 ; 28,0 \mathrm{~g} \mathrm{dm}^{-3}$ de MO; 25,0 mg dm${ }^{-3}$ de P (resina); 74,4 $\mathrm{mmol}_{\mathrm{c}} \mathrm{dm}^{-3} \mathrm{de}$

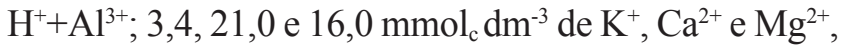
respectivamente; $114,9 \mathrm{mmol}_{\mathrm{c}} \mathrm{dm}^{-3} \mathrm{de} \mathrm{CTC}$ e $35,2 \% \mathrm{deV}$. Para elevar a saturação por bases a $60 \%$, recomendada para a cultura da soja, seriam necessários $2.850 \mathrm{~kg} \mathrm{ha}^{-1}$ de calcário ( $100 \%$ PRNT). No entanto, para evitar excesso de calagem nas camadas superficiais do solo, foram aplicados $1.800 \mathrm{~kg} \mathrm{ha}^{-1}$ de calcário dolomítico (96\% PRNT). A aplicação foi realizada em superfície e sem incorporação.

A semeadura do milheto, do sorgo e da crotalária foi realizada no fim de setembro de 2009, com espaçamento entre linhas de $0,17 \mathrm{~m}$. Do mesmo modo que as culturas de inverno, não foi realizada adubação. 
As subparcelas escarificadas foram mantidas sem a presença de plantas daninhas durante o período de desenvolvimento das plantas de cobertura.

No fim de novembro de 2009, foi semeada a cultura da soja, cultivar CD 216, grupo de maturidade 5.5, de hábito de crescimento indeterminado, com espaçamento entre linhas de $0,45 \mathrm{~m}$. Foi aplicada adubação de semeadura nas doses de 6,60 e $60 \mathrm{~kg} \mathrm{ha}^{-1}$ de $\mathrm{N}, \mathrm{P}_{2} \mathrm{O}_{5}$ e $\mathrm{K}_{2} \mathrm{O}$, respectivamente. A colheita foi realizada no final de março de 2010. As condições meteorológicas ocorridas durante a condução da cultura da soja estão apresentadas na Figura 1.

A atividade radicular da soja foi avaliada conforme Encide-Olibone et al. (2008). Quando a soja encontravase no estádio R4 (Fehr et al., 1971), foi realizada a aplicação de $3 \mathrm{~mL}$ de nitrato de rubídio $\left(\mathrm{RbNO}_{3}\right)$, na concentração de $1,0 \mathrm{~mol} \mathrm{~L}^{-1}$, com auxílio de cateter e seringa graduada, nas distâncias de $0,0,0,11$ e $0,22 \mathrm{~m}$ da planta de referência e nas profundidades de $0,05,0,10$, 0,20, 0,40 e 0,60 m. Para realizar a aplicação, o solo foi perfurado com hastes cilíndricas de $12 \mathrm{~mm}$ de diâmetro. Para cada ponto de aplicação, foram realizadas duas repetições. Após quatro dias da aplicação do $\mathrm{RbNO}_{3}$, a parte aérea das plantas foi coletada e seca em estufa com circulação forçada de ar a $60^{\circ} \mathrm{C}$ por 72 horas. Também foi coletada, por subparcela, uma planta que não recebeu aplicação do marcador. Posteriormente, as amostras foram moídas e realizou-se a digestão nitroperclórica e a determinação do teor de $\mathrm{Rb}$ por absorção atômica (Malavolta et al., 1997).

Após a coleta das plantas para a análise da atividade radicular, foram coletadas amostras de raízes da soja pelo método do trado, nas distâncias de $0,0,0,11$ e $0,22 \mathrm{~m}$ da planta de referência e nas camadas de

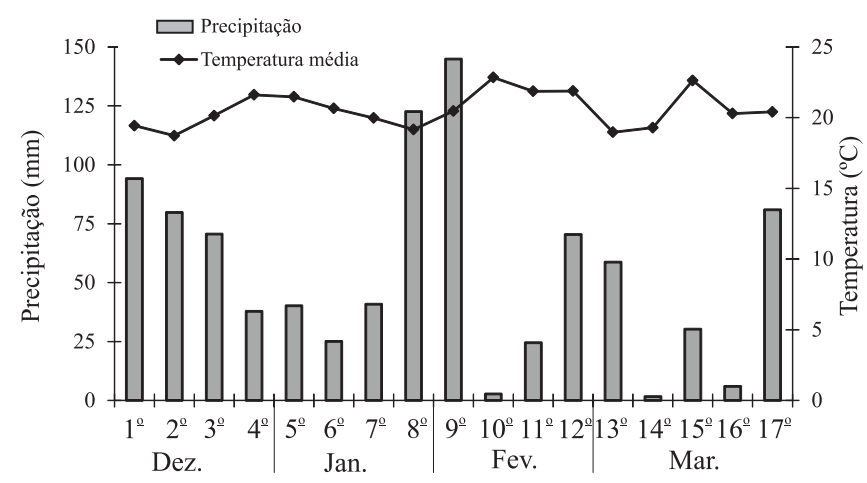

Figura 1. Temperatura média e precipitação acumulada semanal durante o ciclo da cultura da soja, safra 2009/2010.
$0,00-0,05, \quad 0,05-0,10, \quad 0,10-0,20, \quad 0,20-0,40 \quad$ e $0,40-0,60 \mathrm{~m}$, com três subamostras por subparcela. As amostras de raízes foram lavadas sobre peneiras com malha de $1 \mathrm{~mm}$, para separação do solo. A retirada das demais impurezas foi realizada manualmente com auxílio de pinça. Após a limpeza, as amostras foram acondicionadas em recipientes de plástico contendo solução de álcool etílico a 30\% e armazenadas sob refrigeração a $2^{\circ} \mathrm{C}$. As raízes foram submetidas a scanner de leitura ótica, na resolução de 300 dpi, e as imagens digitalizadas foram analisadas com o programa WinRhizo versão 3.8-b (Regent Instrument Inc., Quebec, Canadá), para determinar a densidade de comprimento radicular, conforme Tennant (1975). Para a determinação da produtividade da soja, foi amostrada uma área de $2,25 \mathrm{~m}^{2}$.

Os dados foram submetidos à análise de variância, e as médias foram comparadas pelo teste t (DMS), a $5 \%$ de probabilidade. Foram realizadas análises de correlação de Pearson entre os teores de Rb e a densidade de comprimento radicular. Os coeficientes de correlação foram submetidos ao teste t, a $5 \%$ de probabilidade.

\section{Resultados e Discussão}

A produção de massa de matéria seca das culturas de inverno foi de $1.858 \mathrm{~kg} \mathrm{ha}^{-1}$, para o girassol, e $6.661 \mathrm{~kg} \mathrm{ha}^{-1}$ para o triticale. Na primavera, as plantas de cobertura produziram $3.280,2.730$ e $1.450 \mathrm{~kg} \mathrm{ha}^{-1}$ de massa de matéria seca, para o milheto, o sorgo e a crotalária, respectivamente.

Não foram observadas interações significativas entre as culturas de inverno e os manejos de primavera, para nenhuma das variáveis analisadas. Embora o cultivo do girassol possa resultar em menor densidade de comprimento radicular da soja, em comparação ao triticale, no período de implantação do sistema de semeadura direta (Calonego \& Rosolem, 2010), no presente trabalho, não foram observadas diferenças significativas em função do uso destas culturas de inverno. A raiz da soja, após o cultivo do girassol, apresentou maior crescimento na camada de 0,40 a 0,60 m, na distância de 0,00 m (Figura $2 \mathrm{~A}$ ), enquanto o triticale proporcionou maior crescimento radicular da soja na camada de 0,10 a $0,20 \mathrm{~m}$, na distância de 0,22 m (Figura $2 \mathrm{C}$ ). Assim, o cultivo do girassol em 


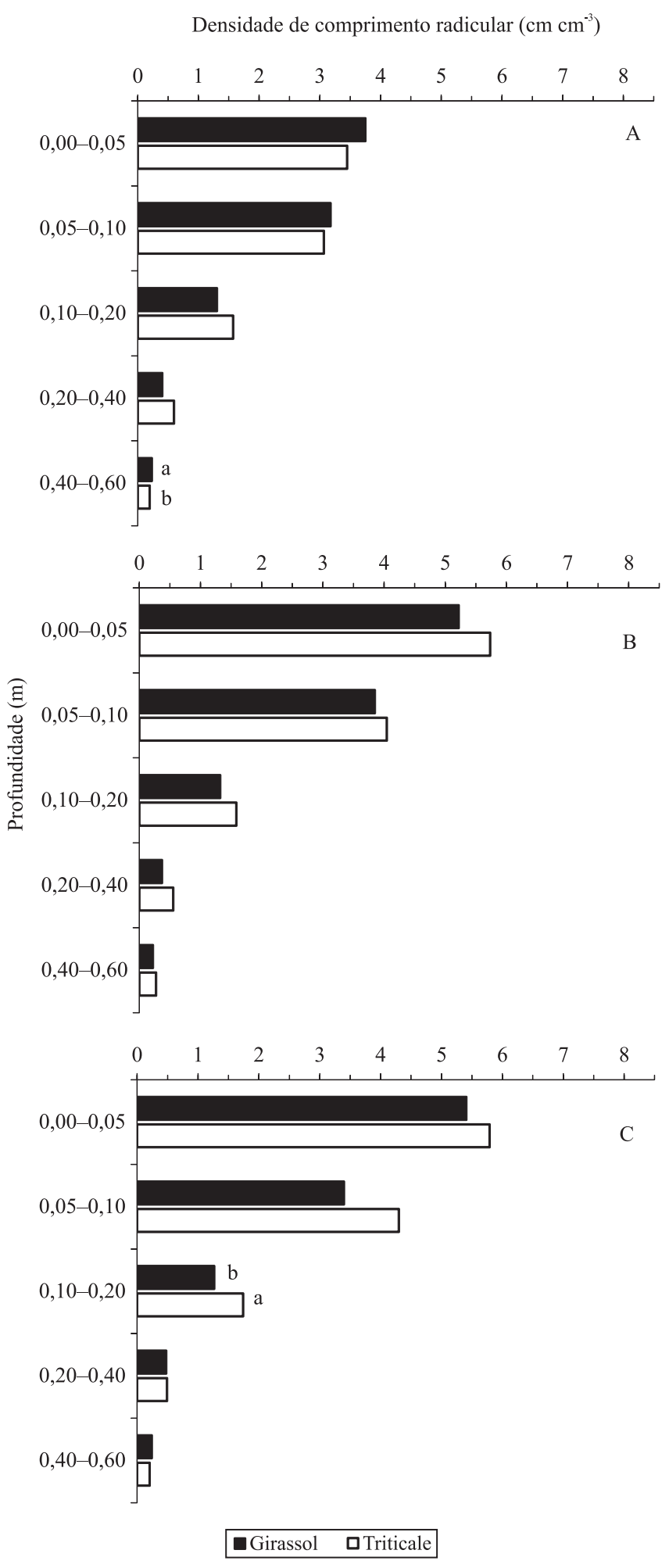

Figura 2. Densidade de comprimento radicular da soja após as culturas de inverno, girassol e triticale, nas distâncias de 0,00 (A), 0,11 (B) e 0,22 m (C) da linha de semeadura. Médias seguidas de letras iguais não diferem entre si pelo teste $\mathrm{t}(\mathrm{DMS})$, a $5 \%$ de probabilidade. longo prazo pode ser utilizado em sistemas de produção sem prejuízo ao crescimento radicular da soja.

Entre os manejos de primavera, observou-se que, de modo geral, a densidade de comprimento radicular da soja foi superior em sucessão ao milheto e ao sorgo até $0,05 \mathrm{~m}$ de profundidade (Figura 3 ). Em geral, a crotalária proporcionou menor crescimento radicular da soja, e a escarificação não diferiu da crotalária. O maior crescimento de raízes em sucessão ao sorgo ou ao milheto está relacionado à maior densidade de comprimento radicular apresentada por essas espécies, o que leva à formação de grande quantidade de bioporos (Calonego \& Rosolem, 2010). O efeito do sorgo e do milheto nas raízes da soja ocorreu inclusive nas camadas mais profundas, a 0,00 e a $0,11 \mathrm{~m}$ de distância da linha de plantio, com superioridade significativa, para ambas as culturas, na camada de 0,20-0,40 m (Figura $3 \mathrm{~A}$ ) e, para o milheto, na camada de $0,40-0,60 \mathrm{~m}$, na distância de $0,11 \mathrm{~m}$ (Figura $3 \mathrm{~B}$ ).

Com o revolvimento recente do solo, poderia se esperar que a escarificação promovesse maior crescimento radicular da soja, em virtude das melhorias de algumas propriedades físicas, como redução da densidade e aumento da macroporosidade do solo, o que não ocorreu. Esse efeito pode estar associado ao tempo de adoção dos sistemas sem revolvimento (sete anos), o que caracteriza sistema de semeadura direta estabilizado, e à redução na agregação do solo, como observado após a primeira escarificação, realizada em 2003 (Calonego \& Rosolem, 2008), que também ocasionou redução do crescimento radicular da soja (Calonego \& Rosolem, 2010).

Da mesma forma que o observado para a densidade de comprimento, a atividade radicular da soja não diferiu significativamente entre as culturas de inverno (Figura 4). Entre os manejos de primavera, a escarificação apresentou a maior atividade na distância de $0,00 \mathrm{~m}$ e na profundidade de $0,10 \mathrm{~m}$, com $119 \mathrm{mg} \mathrm{kg}^{-1}$ de $\mathrm{Rb}$, enquanto o milheto resultou em $38 \mathrm{mg} \mathrm{kg}^{-1}$, o sorgo em $49 \mathrm{mg} \mathrm{kg}^{-1}$ e a crotalária em $59 \mathrm{mg} \mathrm{kg}^{-1}$ (Figura $5 \mathrm{~A}$ ). Na distância de $0,00 \mathrm{~m}$ e na profundidade de $0,40 \mathrm{~m}$, a escarificação proporcionou maior atividade radicular que a crotalária e não se diferenciou dos demais manejos. Nas demais distâncias e profundidades, não foram observadas diferenças significativas. A concentração da atividade radicular mais próxima da superfície, na linha de semeadura, pode ser atribuída às ótimas condições de pluviosidade 


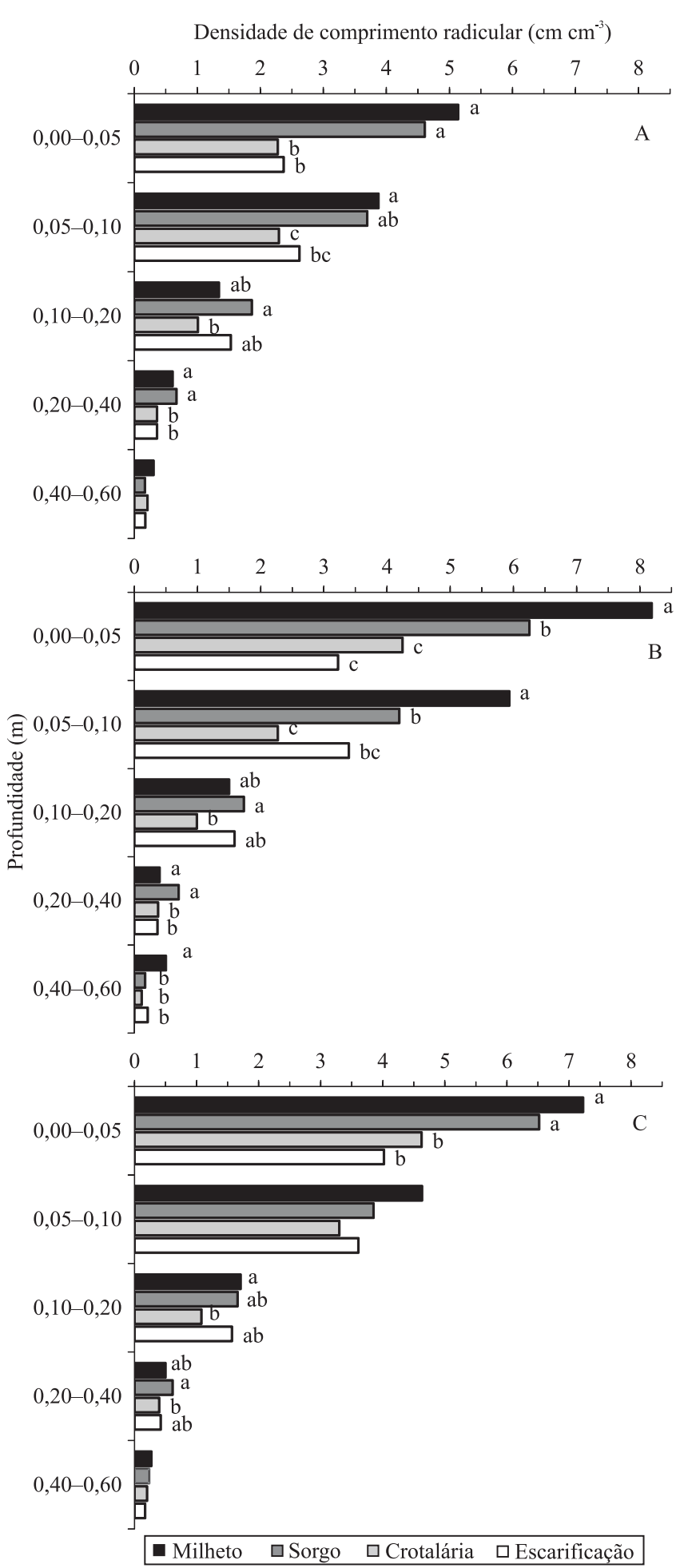

Figura 3. Densidade de comprimento radicular da soja após os manejos de primavera com milheto, sorgo forrageiro, crotalária e escarificação, nas distâncias de 0,00 (A), 0,11 (B) e 0,22 m (C) da linha de semeadura. Médias seguidas de letras iguais não diferem entre si pelo teste $t$ (DMS), a $5 \%$ de probabilidade.

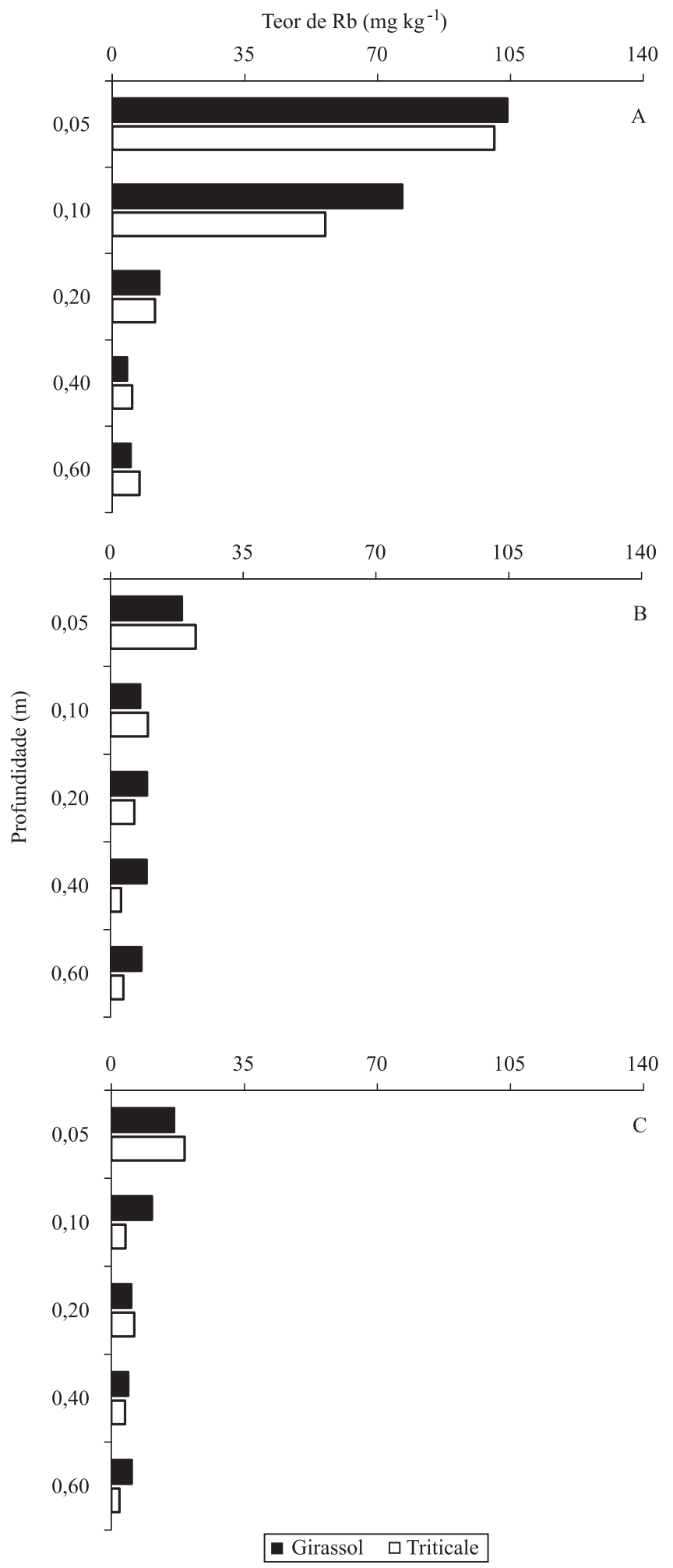

Figura 4. Atividade radicular (teor de $\mathrm{Rb}$ ) da soja após as culturas de inverno, girassol e triticale, nas distâncias de 0,00 (A), 0,11 (B) e $0,22 \mathrm{~m}$ (C) da planta de referência. Não foram observadas diferenças significativas. 


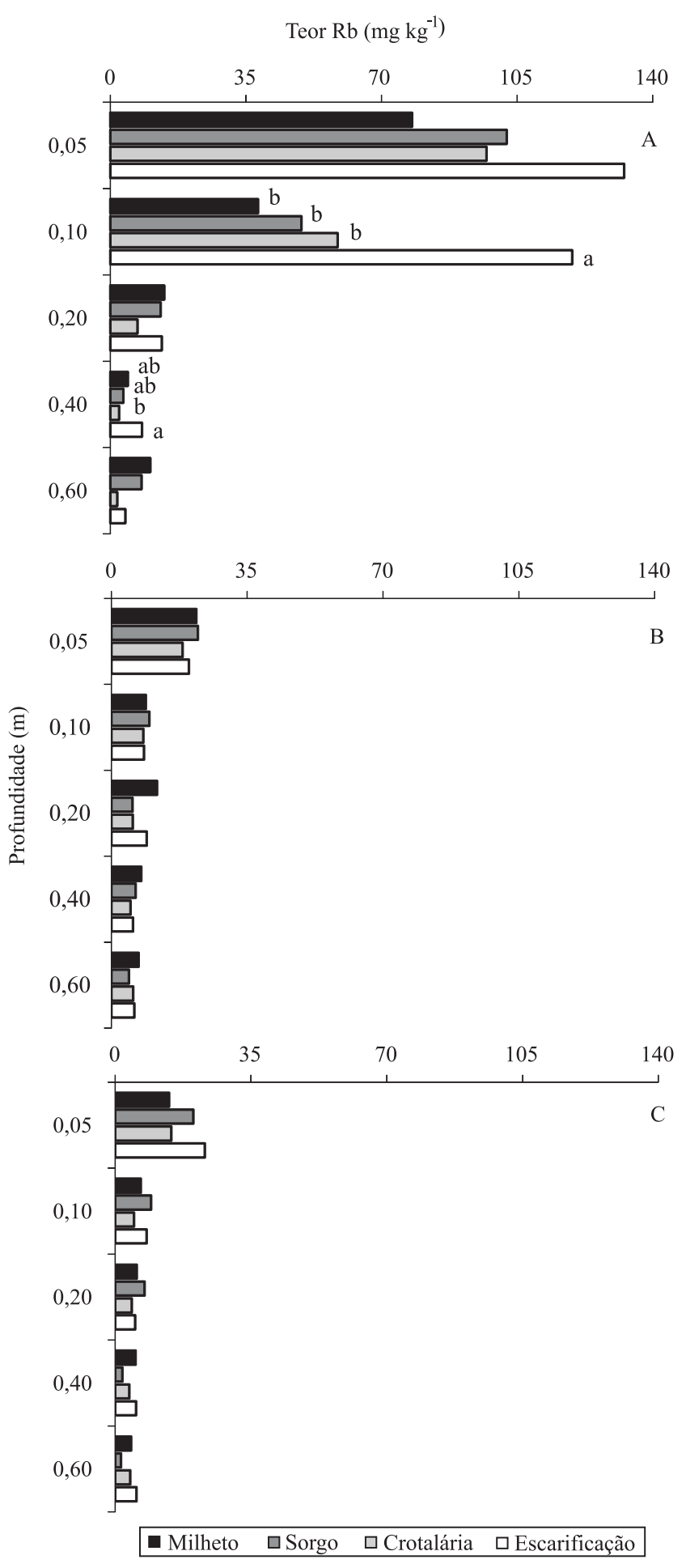

Figura 5. Atividade radicular (teor de $\mathrm{Rb}$ ) da soja após os manejos de primavera com milheto, sorgo forrageiro, crotalária e escarificação, nas distâncias de 0,00 (A), 0,11 (B) e 0,22 m (C) da planta de referência. Médias seguidas de letras iguais não diferem entre si pelo teste $\mathrm{t}$ (DMS), a 5\% de probabilidade. durante todo o ciclo da cultura (Figura 1), associada ao fato de ser esse o local de deposição do fertilizante. Barrios et al. (2006) observaram maior umidade do solo e, consequentemente, maior atividade radicular da soja, na camada superficial do solo sob semeadura direta, em comparação ao sistema convencional. Lehmann (2003) também verificou maior atividade radicular nas camadas superficiais, em épocas chuvosas, em espécies florestais. De acordo com este autor, a atividade radicular é uma característica muito dinâmica.

A correlação entre os teores de $\mathrm{Rb}$ e a densidade de comprimento radicular foi fraca, com valor de 0,25 , mas significativa $(\mathrm{p}<0,01 ; \mathrm{n}=480)$. Algumas características inerentes a cada método podem ajudar a entender esse resultado. No método indireto, a distribuição da atividade radicular foi estimada a partir de plantas isoladas. Já no método do trado, foram amostradas raízes de várias plantas. Com base nos valores médios das profundidades, ou seja, nos dados que variaram em função das distâncias, a correlação foi negativa, com valor de $-0,25$, mas significativa $(\mathrm{p}<0,01 ; \mathrm{n}=96)$. Entretanto, tanto a atividade como a densidade de comprimento apresentaram redução com o aumento da profundidade. Para os valores médios das distâncias, que variaram em função das profundidades, a correlação foi positiva, com valor de 0,63 , e significativa $(\mathrm{p}<0,01 ; \mathrm{n}=180)$.

Uma alternativa para melhor comparar o método do trado com o da atividade radicular seria a aplicação do marcador não apenas em um ponto isolado, mas em uma área maior, o que permitiria a amostragem de mais plantas. Kulmatiski et al. (2010), ao avaliar gramíneas nativas, aplicaram o marcador em 100 pontos, em $1 \mathrm{~m}^{2}$, enquanto O'Sullivan (2008) aplicou o marcador em sulcos, na cultura do inhame (Dioscorea alata L.).

Outra diferença entre os métodos que pode ter contribuído para a baixa correlação está relacionada às profundidades de amostragem. Pelo trado, as amostras são coletadas nas camadas de solo, enquanto, pelo método indireto, o marcador é aplicado em profundidades específicas, ou seja, não é estimada a absorção em todo o volume do solo.

A atividade do sistema radicular é uma característica muito mais dinâmica do que a distribuição física das raízes, o que reduz a correlação entre ambas. Em determinadas condições, como baixa disponibilidade de nutrientes, as raízes das plantas podem apresentar muitas adaptações morfológicas, 
mas essas respostas são lentas quando comparadas às mudanças fisiológicas que podem ser iniciadas dentro de horas (Glass, 2002). Hansen (1974) demonstrou, em macieiras, que a atividade foi praticamente nula sob condições de drenagem deficiente, mesmo com a presença física das raízes.

A produtividade da soja não foi afetada pelas culturas de inverno nem pelos manejos de primavera (Tabela 1). A ausência de resposta da escarificação sobre a produtividade da soja também foi verificada por outros autores, mesmo quando este manejo apresentou melhoria das propriedades físicas (Camara \& Klein, 2005; Lança Rodrígues et al., 2009; Secco et al., 2009). $\mathrm{O}$ aumento da produtividade das culturas com uso da escarificação pode estar associado à quebra de camadas compactadas, o que geralmente ocorre nos primeiros anos de implantação do sistema de semeadura direta ou em áreas com manejo inadequado, com ausência de rotação de culturas. Após a primeira escarificação, no início deste experimento, em 2003, a produtividade da soja foi superior no manejo escarificado (Calonego \& Rosolem, 2010). Como o crescimento radicular da soja foi superior após o cultivo do milheto e do sorgo forrageiro, poder-se-ia esperar aumento na produtividade por maior absorção de água e nutrientes, em virtude do maior volume de solo explorado (Figura 3). Contudo, uma vez que a atividade radicular da soja, após a escarificação, foi superior na profundidade de $0,10 \mathrm{~m}$, na linha de semeadura (Figura $5 \mathrm{~A}$ ), aparentemente houve compensação pelo menor crescimento radicular, o que equilibrou a produtividade. Essa compensação provavelmente só foi possível pela distribuição satisfatória das

Tabela 1. Produtividade da soja após culturas de inverno e de primavera e escarificação ${ }^{(1)}$.

\begin{tabular}{lc}
\hline Manejos & Produtividade da soja $\left(\mathrm{kg} \mathrm{ha}^{-1}\right)$ \\
\hline Girassol & Culturas de inverno \\
Triticale & 3.918 \\
CV (\%) & 3.824 \\
\hline & 19,29 \\
Milheto & Culturas de primavera e escarificação \\
Sorgo & 3.963 \\
Crotalária & 3.780 \\
Escarificação & 3.849 \\
\hline CV $(\%)$ & 3.891 \\
(1) Significância estatística das fontes de variação: culturas de inverno, \\
p=0,747; manejos de primavera, $\mathrm{p}=0,799 ;$ interação entre fatores, $\mathrm{p}=0,112$.
\end{tabular}

precipitações durante todo o ciclo da cultura (Figura 1).

A utilização dos métodos de avaliação radicular depende das características inerentes de cada experimento. Se a pesquisa estiver mais relacionada às propriedades do solo que limitem ou impeçam o crescimento radicular, ou que afetem a sua distribuição física, a avaliação direta pode ser a mais adequada. No entanto, para determinar, não apenas a presença das raízes, mas também se essas raízes estão vivas e ativas, absorvendo água e nutrientes e contribuindo para a produção da planta, a avaliação da atividade radicular pode ser a mais apropriada.

\section{Conclusões}

1. A distribuição e a atividade do sistema radicular da soja são independentes da espécie cultivada no inverno.

2. O crescimento radicular da soja é favorecido pelo cultivo do milheto e do sorgo forrageiro na primavera.

3. A medida direta do sistema radicular da soja, pelo método do trado, apresenta baixa correlação com a avaliação da atividade radicular.

\section{Agradecimentos}

À Fundação de Amparo à Pesquisa do Estado de São Paulo e ao Conselho Nacional de Desenvolvimento Científico e Tecnológico, pelo apoio financeiro.

\section{Referências}

BARRIOS, M.B.; BOZZO, A.A.; DEBELIS, S.P.; PEREYRA, A.M.; BUJÁN, A. Soil physical properties and root activity in a soybean second crop/maize rotation under direct sowing and conventional tillage. Spanish Journal of Agricultural Research, v.4, p.355-362, 2006.

BERTOL, I.; COGO, N.P.; LEVIEN, R. Erosão hídrica em diferentes preparos do solo logo após as colheitas de milho e trigo, na presença e na ausência dos resíduos culturais. Revista Brasileira de Ciência do Solo, v.21, p.409-418, 1997.

CALONEGO, J.C.; ROSOLEM, C.A. Estabilidade de agregados do solo após manejo com rotações de culturas e escarificação. Revista Brasileira Ciência do Solo, v.32, p.1399-1407, 2008.

CALONEGO, J.C.; ROSOLEM, C.A. Soybean root growth and yield in rotation with cover crops under chiseling and no-till. European Journal of Agronomy, v.33, p.242-249, 2010.

CAMARA, R.K.; KLEIN, V.A. Propriedades físico-hídricas do solo sob plantio direto escarificado e rendimento da soja. Ciência Rural, v.35, p.813-819, 2005. 
CARVALHO FILHO, A.; CENTURION, J.F.; SILVA, R.P. da; FURLANI, C.E.A.; CARVALHO, L.C.C. Métodos de preparo do solo: alterações na rugosidade do solo. Engenharia Agrícola, v.27, p.229-237, 2007.

ENCIDE-OLIBONE, A.P.; OLIBONE, D.; ROSOLEM, C.A. Atividade radicular da soja: definição de um método. Revista Brasileira de Ciência do Solo, v.32, p.899-903, 2008.

FANTE JÚNIOR, L.; REICHARDT, K.; JORGE, L.A.C.; CRESTANA, S. Distribuição do sistema radicular do milho em terra roxa estruturada latossólica: I. Comparação de metodologias. Scientia Agricola, v.51, p.513-518, 1994.

FEHR, W.R.; CAVINESS, C.E.; BURMOOD, D.T.; PENNIGTON, J.S. Stage of development descriptions for soybeans, Glycine max (L.) Merrill. Crop Science, v.11, p.929-931, 1971.

GENRO JUNIOR, S.A.; REINERT, D.J.; REICHERT, J.M. Variabilidade temporal da resistência à penetração de um latossolo argiloso sob semeadura direta com rotação de culturas. Revista Brasileira de Ciência do Solo, v.28, p.477-484, 2004.

GLASS, A.D.M. Nutrient absorption by plant roots: regulation of uptake to match plant demand. $3^{\text {rd }}$ ed. In: WAISEL, Y.; ESHEL, A.; KAFKAFI, U. (Ed.). Plant roots: the hidden half. New York: Marcel Dekker, 2002. p.571-586.

HAMZA, M.A.; ANDERSON, W.K. Soil compaction in cropping systems, a review of the nature, causes and possible solutions. Soil and Tillage Research, v.82, p.121-145, 2005.

HANSEN, P. Drainage depth for apple trees. Tidsskrift for Planteavl, v.78, p.46-52, 1974.

KULMATISKI, A.; BEARD, K.H.; VERWEIJ, R.J.T.; FEBRUARY, E.C. A depth-controlled tracer technique measures vertical, horizontal and temporal patterns of water use by trees and grasses in a subtropical savanna. New Phytologist, v.188, p.199-209, 2010.

LANÇA RODRÍGUES, J.G.; GAMERO, C.A.; COSTA FERNANDES, J.; MIRÁS-AVALOS, J.M. Effects of different soil tillage systems and coverages on soybean crop in the Botucatu Region in Brazil. Spanish Journal of Agricultural Research, v.7, p.173-180, 2009.

LEHMANN, J. Subsoil root activity in tree-based cropping systems. Plant and Soil, v.255, p.319-331, 2003.
LYNCH, J. Root architecture and plant productivity. Plant Physiology, v.109, p.7-13, 1995.

MALAVOLTA, E.; VITTI, G.C.; OLIVEIRA, S.A. de. Avaliação do estado nutricional das plantas: princípios e aplicações. 2.ed. Piracicaba: Associação Brasileira para Pesquisa da Potassa e do Fosfato, 1997. 319p.

MUZILLI, O. Manejo do solo em sistema plantio direto. In: CASÃO JUNIOR, R.; SIQUEIRA, R.; MEHTA; Y.R.; PASSINI, J.J. (Ed.). Sistema plantio direto com qualidade. Londrina: IAPAR, 2006. p.9-27.

O'SULLIVAN, J.N. Root distribution of yam (Dioscorea alata) determined by strontium tracer. Experimental Agriculture, v.44, p.223-233, 2008 .

RAIJ, B. van; ANDRADE, J.C. de; CANTARELLA, H.; QUAGGIO, J.A. (Ed.). Análise química para avaliação da fertilidade de solos tropicais. Campinas: Instituto Agronômico, 2001.285p.

RUSSELL, R.S.; ELLIS, F.B. Estimation of the distribution of plant roots in soil. Nature, v.27, p.582-583, 1968.

SANTOS, H.G. dos; JACOMINE, P.K.T.; ANJOS, L.H.C. dos; OLIVEIRA, V.A. de; OLIVEIRA, J.B. de; COELHO, M.R.; LUMBRERAS, J.F.; CUNHA, T.J F. (Ed.). Sistema brasileiro de classificação de solos. 2.ed. Rio de Janeiro: Embrapa Solos, 2006. $306 \mathrm{p}$.

SECCO, D.; REINERT, D.J.; REICHERT, J.M.; SILVA, V.R. da. Atributos físicos e rendimento de grãos de trigo, soja e milho em dois Latossolos compactados e escarificados. Ciência Rural, v.39, p.58-64, 2009.

SILVA, R.H. da; ROSOLEM, C.A. Crescimento radicular de soja em razão da sucessão de cultivos e da compactação do solo.

Pesquisa Agropecuária Brasileira, v.37, p.855-860, 2002.

STONE, L.R.; SILVEIRA, P.M. da. Efeitos do sistema de preparo e da rotação de culturas na porosidade e densidade do solo. Revista Brasileira de Ciência do Solo, v.25, p.395-401, 2001.

TAIZ, L.; ZEIGER, E. Fisiologia vegetal. Porto Alegre: Artmed, 2004. 719p.

TENNANT, D. A test of a modified line intersect method of estimating root length. Journal of Ecology, v.63, p.995-1001, 1975.

$\overline{\text { Recebido em } 27 \text { de maio de } 2011 \text { e aprovado em } 31 \text { de outubro de } 2011}$ 